\title{
Realigning research and extension to focus on farmers' constraints and opportunities
}

\author{
S.S. Snapp ${ }^{\mathrm{a}, *}$, M.J. Blackie ${ }^{\mathrm{b}}$, C. Donovan ${ }^{\mathrm{c}}$ \\ ${ }^{a}$ Department of Crop and Soil Sciences and Department of Horticulture, Michigan State University, \\ East Lansing, MI 48824, USA \\ ${ }^{\mathrm{b}}$ University of East Anglia, Norwich, Norfolk NR4 7TJ, UK \\ ${ }^{\mathrm{c}}$ Department of Agricultural Economics, Michigan State University, East Lansing, MI 48824, USA
}

\begin{abstract}
This paper argues that research and extension have failed to (1) develop technologies that take into account farmers' resource constraints and risks; and (2) improve farmers' capacity to adapt technologies to their own situations. The paper critiques continued use of blanket, high-dose fertilizer recommendations, arguing for approaches that teach farmers how to maximize returns from smaller, more affordable input purchases. Developing such technologies requires that researchers integrate a wider range of stakeholders (farmers, extension agents, agricultural exporters and processors) into research activities at an earlier point in time than has been the case. Although evidence that these new approaches are increasing the use of purchased inputs remains weak, a number of important lessons are emerging about how research and extension outcomes are influenced by institutional culture and incentives. The authors conclude that developing recommendations for small, affordable input doses and training farmers so they can adapt recommendations to their particular circumstances is as much an institutional challenge as a technology challenge.

(C) 2003 Elsevier Ltd. All rights reserved.
\end{abstract}

Keywords: Research; Extension; Fertilizer; Inputs; Institutions; Culture

\section{Introduction}

If agricultural productivity is to grow in Africa, research and extension (R\&E) services need to develop and disseminate science-based information about improved technologies that address the resource constraints and risks faced by the

\footnotetext{
${ }^{*}$ Tel.: +1-517-355-5187; fax: +1-517-432-2242.

E-mail address: snapp@msu.edu (S.S. Snapp).
} 
majority of Africa's farmers. Front-line extension staff frequently complain about the lack of yield-increasing technologies designed to take into account the resources and goals of Sub-Saharan Africa's (SSA) resource-poor farmers (Ahmed et al., 1997). Limited adoption of recommended technologies is also indicative of a disconnect between R\&E and African smallholders (Meertens, 2003).

We argue in this paper that the evolving market situation brought about by economic reforms in SSA calls for an R\&E shift from fine-tuning high-input recommendations for inorganic fertilizers to a focus on giving farmers information and skills that will help them to optimize economic and biological returns to small investments in technologies of relevance to both cereal and export crops. We review recent experiences in southern and eastern Africa that show promise in this respect. These experiences include: incorporating rainfall risk into fertilizer recommendations, simulation modeling to compare potential outcomes of different choices using limited resources, and research on combining organic and inorganic nutrient sources.

In addition to describing new methods that focus on flexible technologies, we use a Malawi R\&E project to illustrate how incentive structures and organizational culture influence technology development and delivery of services to smallholders. This is followed by a review of recent 'market-driven' technology development efforts that provide multi-institutional alternatives to traditional SSA researcher-led approaches.

\section{Durability of high input fertilizer research and recommendations}

There is a fundamental disconnect between the issues that African R\&E services tend to address, and the resources and problems faced by farmers. The literature is replete with discussions of the need to use incremental, flexible approaches to recommendations that take into account local resources and profitability instead of focusing on blanket, package recommendations that maximize yields (Okali et al., 1994). Yet, governments and donors continue to fund extensive, countrywide trials in SSA examining minor variations on high rates of costly inputs and different fertilizer types. From 1988 to 1993, fertilizer rate response trials were conducted throughout Kenya, Malawi and Zambia (Wendt, 1993; FURP, 1994; Donovan et al., 2002). In Malawi, extensive fertilizer response trials had been conducted forty and twenty years earlier (Brown, 1962), and during the late 1990s, countrywide trials were once again initiated to verify maize response to fertilizer in the range of 55-110 kg nutrients/ha (Benson, 1997) (see Table 1). Over the same time period, demonstrations of maize response to fertilizer were conducted using similar levels in Mozambique (Howard et al., 2000). Despite these efforts, average SSA fertilizer use is stalled at about $10 \mathrm{~kg} / \mathrm{ha}$ in SAA, and in poorer countries it is frequently much lower.

There are examples from SSA where substantial progress has been made in developing technologies that maximize returns from small investments (Dimes et al., 2002; Kamanga et al., 2001). Yet, even in these situations government pro- 


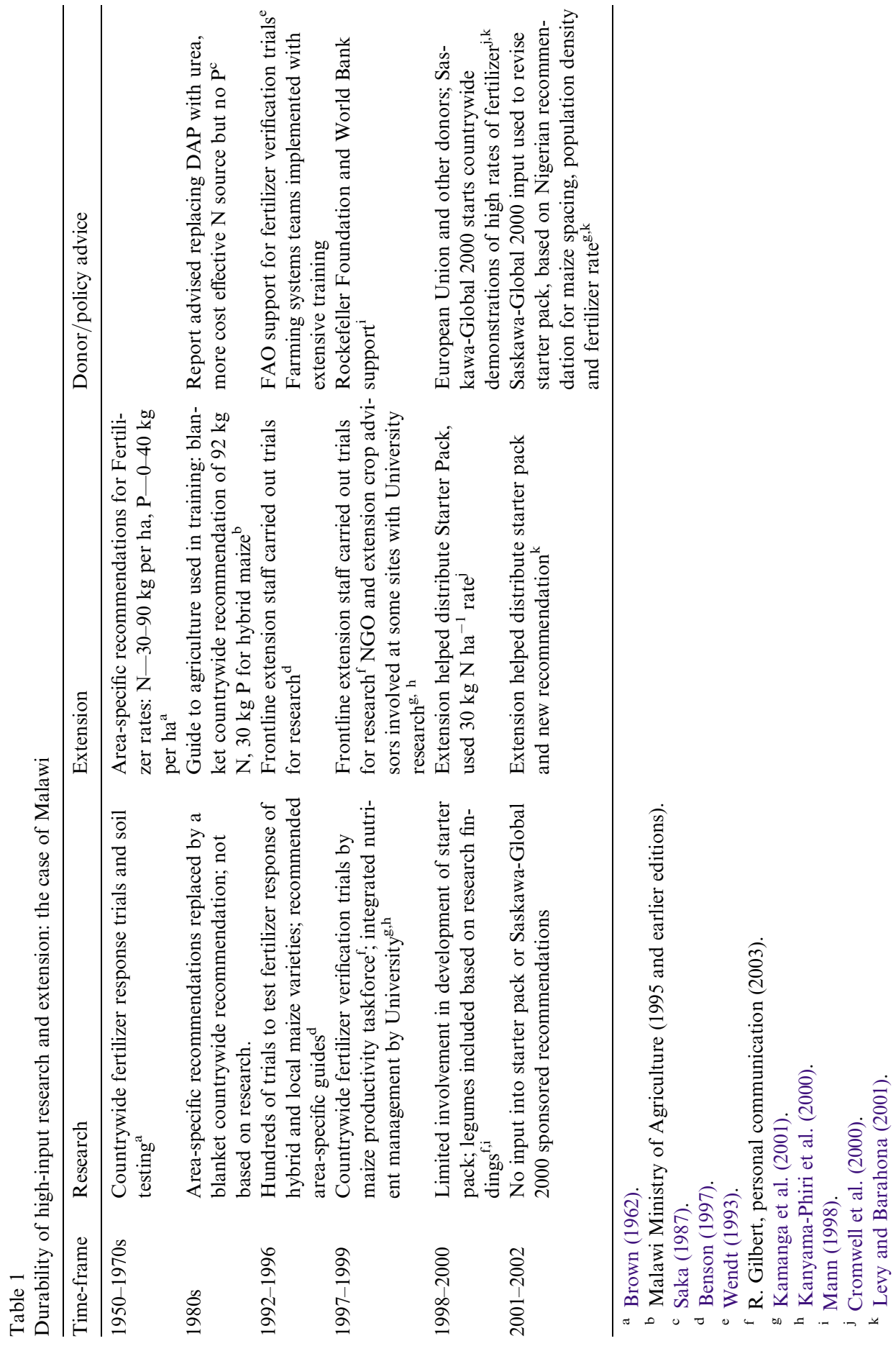


grams and donor-supported initiatives have tended to promote high-input recommendations. Senior and frontline extension workers from Zimbabwe have actively participated in a number of modeling and participatory projects to develop more appropriate recommendations for semi-arid environments, yet change has not yet been implemented in extension recommendations (Dimes et al., 2002; Snapp et al., 1998). Malawi is another case in point. Donors have promoted countrywide efforts at periodic intervals to develop area-specific fertilizer recommendations for maize (Table 1), as well as smaller projects evaluating fertilizer response (Wendt, 1993). Interviews of frontline extension staff suggest, however, that officially recommended rates, ${ }^{1}$ or in many cases higher rates, are still promoted (Snapp et al., 2002b).

Information generated in countrywide verification trials was incorporated in the design of a small package of improved seed and fertilizer distributed to almost every rural household under Malawi's Starter Pack (SP) program (Mann, 1998). Promotion of farmer experimentation with new germplasm, cereal-legume intercropping systems and small amounts of fertilizer targeted to planting stations (seed pockets) was central to this countrywide effort (Blackie and Gibbon, 2003; Cromwell et al., 2000). In the third year a technical message was included that contradicted earlier advice: it promoted single- spaced maize (rather than pockets which allowed intercrops) at high population densities and a blanket, high fertilizer rate. This new recommendation was developed by Saskawa-Global 2000 (SG2000) based on Nigerian research (Kamanga, 2002). SG2000 discussions at the highest government levels, and considerable financial incentives, set the stage for wide-scale promotion of this message. Reviewers of the program commented on the conflicting technical advice and the missed opportunity to disseminate consistent information with inputs (Levy and Barahona, 2001).

Why do adaptive research trials on high rates of fertilizer persist in the face of evidence that they do not improve fertilizer uptake among smallholders? In other regions of the world, productivity gains have been associated with increased use of inorganic fertilizer and this relationship may drive much of the fascination with trials testing fertilizer sources, rates and timing. Also, genetic research can only improve yields so far; fertility enhancement and crop management are essential ingredients to further gains. Though the arguments for increasing fertilizer use are compelling, substantial growth in fertilizer use is unlikely unless barriers faced by smallholder farmers are addressed.

\section{Developing technologies that take into account risk and farmer resources}

Among the most frequently cited constraints to greater use of inputs by smallholders are production and price risks and resource availability. There is growing consensus that productivity-enhancing technologies are relevant to the extent that

\footnotetext{
${ }^{1}$ For the last $25 \mathrm{yr}$, the countrywide, blanket fertilizer recommendation for hybrid maize reported in the Guide to Malawi Agriculture has been $92 \mathrm{~kg}$ nitrogen and $40 \mathrm{~kg}$ phosphate.
} 
they can enable farmers with limited resources to increase productivity in high-risk environments. The development of appropriate recommendations requires $\mathrm{R} \& \mathrm{E}$ efforts that emphasize an understanding of farmer resource levels and risk. Smallholders in SSA confront considerable price risk for inputs and outputs, as well as a wide range of production risks.

\section{The consequences of price risk}

Purchasing an external input such as inorganic fertilizer requires a financial commitment by farmers. When the prices for the output are highly variable, as is common in much of SSA for most commodities, it becomes risky to make the investment, in spite of high yield responses. An analysis of Mozambique's SG2000sponsored fertilizer demonstrations showed that profitability was critically dependent on the price obtained for the output (Howard et al., 2000). Given market volatility, selling maize at harvest may mean a price that is only $25-40 \%$ of the price that is seen six months later. If the farmers in the SG2000 trials sold their maize in June, which the vast majority of food-insecure farmers must do, only $36 \%$ would make a profit using the recommended SG2000 package.

A similar pattern was seen in Malawi: a countrywide test of maize fertilizer recommendations showed that biological response of grain yield to fertilizer was consistently high, yet profitability varied markedly (Benson, 1997). Less than 10\% of sites indicated profitable application of the lowest rate tested, $45 \mathrm{~kg}$ nutrients/ ha. If maize was sold later in the year, at double the price obtained at harvest, then $55 \%$ of sites showed a profitable response. However, the majority of farmers sell at harvest. It is not surprising that a survey in Central Malawi showed only $30 \%$ of farmers used fertilizers (much lower rates among female-headed households), and the average rate among those using it was about $40 \mathrm{~kg}$ of nutrients/ha (Levy and Barahona, 2001; Snapp et al., 2002b).

\section{Taking into account production risk and limited resources}

The highly variable environment of the semi-arid topics limits farmer ability to evaluate potential returns to investments in seeds and fertilizer. The drier areas of Zimbabwe communal lands require skilled fertilizer and manure management. Nutrients must be applied so as to foster crop response while not concentrating salts near young seedlings and inadvertently burning the crop (Snapp et al., 1998). Higher doses of fertilizer are not successful in raising productivity in low rainfall years. Simulation modeling offers a means to test yield response over time under different weather conditions. Scenarios comparing a range of investment strategies can be evaluated including using fertilizer at different doses and comparing tradeoffs with other investments, such as hiring labor to allow early planting or extra weeding.

To test the relevance of simulation models for developing risk-reducing recommendations, a project was initiated in southern Zimbabwe involving extension staff, crop modelers, agronomists, NGOs and farmers (Rohrbach and Okwach, 1998). The goal was not only to test the performance of crop advice under variable 
weather scenarios but also to develop flexible guidelines that took into account farmers' limited access to land, labor and cash. On-farm survey data and group discussions with farmers were used to determine a representative range of resources available for a typical farm, including access to labor and fertilizer. Crop response over time was modeled for scenarios that evaluated trade-offs among planting time, low versus high doses of fertilizer and low versus high investments in weeding (Dimes et al., 2002). Long-term weather data were used to compare yield stability over time as a function of an extensive strategy for the entire farm-where fertilizer and weeding were applied at a low level throughout the farm-versus a strategy where part of the farm was intensively weeded and fertilized.

The current recommendation from the Zimbabwe Ministry of Agriculture is to combine fertilizer with weed-free management through three tillage operations per crop. Yet, only the first weeding was observed to be critical in modeling sessions and complementary on-farm trials. The combination of one early weeding and a small amount of fertilizer (18 kg N/ha) increased yields two-fold, to $1300 \mathrm{~kg} / \mathrm{ha}$ (Dimes et al., 2002). It was surprising to participating agronomists that a second weeding had no detectable further benefit, in this risky environment. This experience suggests that researchers' use of simulation modeling to evaluate trade-offs among investments can contribute to improved relevance of recommendations (Dimes et al., 2002).

The risk of losing a fertilizer investment in poor rainfall years must be considered in semi-arid regions, particularly for marginal soil types where smallholder farms tend to be located. This risk can be minimized through a 'response farming' technique that uses early rainfall events to decide on the amounts of fertilizer to apply in a given season (Piha, 1993). The key to the system is flexibility in fertilizer application, with low initial doses applied when early rainfall is inadequate and higher doses applied when early rainfall is promising. Over a five-year period, response farming gave $25-42 \%$ more yield and $21-41 \%$ more profit than did existing fertilizer recommendations. In favorable rainfall years, participating farmers' profits were $105 \%$ higher than those of a control group of comparably good farmers in the area. Participant loan repayment was excellent at $90 \%$. An NGO and Piha's group worked to carry out campaigns in selected project areas to scale up the package through associated savings clubs. In the 1999/2000 season, some 500 farmers formed 53 savings clubs. A focus on reducing risk rather than optimizing yield has helped make fertilizer use profitable for these poor farmers in Zimbabwe.

\section{Stabilizing and enhancing returns to small investments in fertilizers}

Given the large numbers of smallholders who use fertilizers at very low rates, more attention is needed on ways to maximize response to small amounts. There is promising research indicating that organic inputs from crop residues, livestock manure and green manures can enhance fertilizer efficiency and enhance yields (Palm et al., 1997; Place et al., this issue). The benefits of integrating organic and inorganic nutrient sources have been observed for widely disparate soil types and climates, from a quarter of a century trial on manure and fertilizer in sub- 
humid Kenya to a decades-long trial on sorghum response to residue and manure incorporation with micro amounts of fertilizer in arid regions of Niger (Enyong et al., 1999).

Incorporation of legumes into cropping systems is a particularly effective means of enhancing nutrient availability at a minimal cost. Some species of shrubby legumes not only biologically fix $\mathrm{N}$, but also improve availability of phosphorus, and thus increase crop yields (Snapp and Silim, 2002). A long-term Zimbabwe study found that grain yield and profitability can be increased by $50 \%$ or more if fertilizer is applied to maize after a grain legume rotation, or a maize-legume intercrop, compared to continuous maize (Waddington and Karigwindi, 2001). Onfarm studies in Malawi indicate that integration of green manures can enhance fertilizer use efficiency in maize-based systems from $35 \%$ to $70 \%$ (Kamanga et al., 2001). At the same time there are considerable constraints to farmer adoption of legumes, including high labor requirements and lack of access to seed (Meertens, 2003). To promote less risky use of fertilizer through integration with legumes requires agronomists and natural resource scientists to widen the range of collaborators to include social science and other stakeholders (Franzel and Scherr, 2002). Profitability of technologies that involve legumes or other productivity enhancements will depend on market opportunities, grain price and the fertilizer to crop price ratio.

\section{Learning from recent efforts to develop efficient, low-cost technologies}

\section{Novel approaches to developing technologies}

A project in Malawi to develop soil-fertility enhancing technologies provides some insights into the R\&E process, including strengths and weaknesses of the institutions involved (Snapp et al., 2002a). The project had aspects of a natural experiment: different organizations were the primary responsible agent at different sites. This allowed a comparison of outputs and impacts at different sites. Altogether six sites were involved, two sites led by NGOs, two sites led by the University of Malawi, and two sites led by the Government of Malawi Department of Research and Technical Services (DARTS). Smallholder farmers and extension field staff were involved at all sites. The anticipated outputs from this project included improved technologies that were appropriate to farmer resources and goals and farmer capacity building, to facilitate local adaptation and testing of technologies. Other goals were to train future researchers, publish articles documenting research findings and to foster farmer uptake of improved crop and soil management practices through disseminating new recommendations.

The project used a novel methodology, the mother and baby (M\&B) participatory trial design. The $\mathrm{M} \& \mathrm{~B}$ design systematically links a central 'mother trial' managed by researchers to numerous farmer-managed 'baby' trials (Snapp et al., 2002a). The central mother trial tests a large number of best bet technologies or varieties and is replicated within a site, whereas the baby trials are each a par- 
tial replicate and test a smaller sub-set of technologies. This facilitates a rigorous cross-check of biological performance with farmer assessment. Communication among researchers, extension staff and farmers is facilitated, ideally permitting researchers to better understand farmer decision-making.

The teams developed low-cost recommendations at all sites. This included integration of multi-purpose grain legumes and green manures with maize, targeted use of low doses of fertilizer and manure, and a 'doubled-up' legume-legume intercrop system rotated with maize (Kanyama-Phiri et al., 2000; Snapp et al., 2002a). The type of legume that was the best biomass or grain producer varied with agro-ecozone. Pigeon pea intercrops with maize and other crops were consistently profitable at a number of sites when combined with small amounts of fertilizer $(60 \%$ more profitable than fertilizer applied to maize alone).

The insights gained in the initial three years of trials were almost immediately used to help develop the Starter Pack (SP) program package of regionally targeted inputs. This was distributed to the vast majority of smallholder farmers in Malawi (Mann, 1998). The SP program provided a vehicle for rapidly and widely disseminating information and resources. This permitted farmers to optimize fertilizer efficiency and crop response to limited inputs through fertilizer targeting. It is difficult to determine how much favorable weather influenced aggregate food production, but the initial two years of the SP distribution were associated with higher than average crop yields and many believe that the SP contributed to this (Levy and Barahona, 2001).

\section{Institutional context matters}

The character of the lead implementing institution appears to have affected the other outputs obtained from the M\&B trial experience. Farmer capacity building was strongest at the NGO-led sites. These were the only sites with significant (though small) levels of farmer uptake beyond the project villages. This was the conclusion of an independent assessment conducted by the Participatory Research and Gender Analysis (PRGA) system-wide initiative of the CGIAR (Johnson et al., 2002). The project provided the same training in participatory methodology and resources at all sites yet farmers had greater input and received more training at NGO-led sites. University-led sites tended to conduct relatively complex baby trials (Johnson et al., 2002). This may have made it more difficult for farmers to understand the technologies and adapt them. Professional capacity building and research documentation was very strong at University-led sites, including three MS theses, five refereed articles and two extension bulletins (Kanyama-Phiri et al., 2000; Kamanga, 1999; Kamanga et al., 2001; Phiri et al., 1999a, 1999b; Snapp et al., 2002a, 2002b). Researchers from government DARTS produced solid technical recommendations, but DARTS sites had mediocre performance in terms of farmer capacity building and publications (Johnson et al., 2002).

The reward structure, relative opportunities and institutional culture varied with lead organization. There was a strong correspondence between outputs and institutional expectations: University staff are promoted on the basis of publications 
produced and number of students who graduate; NGOs are frequently assessed by donors on farmer capacity building and dissemination of technologies; Government DARTS staff generally receive minimal rewards and a low profile may be required to move up into more lucrative administrative jobs. This bureaucratic structure may not be conducive to conducting research focused on impacts at the farm level, or on trying out new trial designs.

The Malawi experience has implications for design of $\mathrm{R} \& \mathrm{E}$ programs. It illustrates that a standard trial methodology such as M\&B will not necessarily lead to the same outputs if different institutions implement it. Using participatory approaches and methods does not guarantee that concerns of farmers will be heard and acted on by researchers. It is too early to tell if lead institutions influenced adoption (Kanyama-Phiri et al., 2000; Snapp et al., 2002a, 2002b). Follow-up surveys to assess adoption patterns across sites would seem to merit priority attention. Farmer-appropriate recommendations were developed but wide-scale adoption may require further steps. Relative strengths of different organizations were documented, where NGOs excelled in farmer capacity building and University staff in conducting on-farm research. Multi-institutional approaches may be a way forward, although the reward structure of the government research department appeared to make it a poor leader in implementing innovative methods in R\&E. An institutional context resistant to change may be one reason that the new recommendations incorporated in the SP program were abandoned in the third year, when the government-run SP program reverted to more familiar high input technologies.

\section{Different views of participatory technology development}

Participatory research methodologies have been widely advocated as means to improve research outcomes and local capacity to conduct adaptive research (Braun et al., 2000; Farrington, 1995; Franzel and Scherr, 2002). Definitions vary, but here we address approaches that help build quality farmer-researcher partnerships, and in particular 'upstream,2 participatory methodology that rigorously documents farmer preferences and decision making to improve research relevance, with the ultimate goal of facilitating wider adoption (Snapp and Heong, 2003). Examples of successful participatory approaches include surveys and focus groups to document farmer knowledge, use of expert farmer panels, and incorporation of farmer views into criteria used to rate performance (Sperling et al., 2001). Repeated failures of conventional approaches to breeding subsistence crops such as common bean and cowpea led breeders to experiment with participatory methods (Kitch et al., 1998). Wider adoption of varieties was observed once farmer criteria were systematically incorporated, including labor efficiency, taste, cooking qualities, multiple use (e.g.,

\footnotetext{
${ }^{2}$ Upstream can be defined as participatory methodology that is researcher-led and focuses primarily on improving the quality of research and less on local community and farmer capacity building (Johnson et al., 2002).
} 
fodder as well as food) and intercrop ability, along with conventional selection criteria such as yield, disease suppression and maturity.

Development of participatory natural resource management (NRM) methods has been a slower process than uptake of participatory methods by plant breeders (Johnson et al., 2002). This is in part due to the differences in types of knowledge generated. There are considerable labor and cash investment hurdles that farmers must overcome to adopt management practices, and agronomic responses tend to be highly variable and locally specific. NRM technologies usually involve combinations of practices that require higher management skills, as well. Integrated decision-making about sustainable and effective use of resources is difficult to distill into small information bits or to codify and distribute, in contrast to genetic information (Snapp and Heong, 2003).

A case in point is how different disciplines view the $M \& B$ participatory trial design (Snapp et al., 2002a). Plant breeders have rapidly adopted this design, after developing improved statistical models for incorporating farmer ranking effectively with repeatable estimates of variability and variety performance (Atlin et al., 2002). Four years after its introduction, nine plant breeders on three continents are using the trial designs, including region-wide trials to improve cereal and legume variety selection (Morrone and Snapp, 2001). Soil scientists and agronomists who have tried the $M \& B$ trial design are more cautious: a survey indicated that $45 \%$ saw M\&B trials as an effective way to reach farmers, yet the associated costs were seen as prohibitive (Snapp et al., 2002a). Interestingly, a cost benefit assessment by PRGA found costs to be comparable to conventional approaches, after initial training investments in participatory techniques (Johnson et al., 2002). Plant breeders indicate they are adopting $\mathrm{M} \& \mathrm{~B}$ designs precisely because it is an inexpensive way to evaluate traits over a broader environment and to involve more clients (Atlin et al., 2002).

Comparing crop management and plant breeding approaches to participatory methodology may not be fair. The complexity of crop production technologies requires multidisciplinary and collaborative efforts among agronomists, soil scientists, geographers, agricultural economists, anthropologists and modelers to conduct systems analysis of opportunities and costs associated with technologies (Blackie and Gibbon, 2003). At the same time, differences in assessment processes for the different disciplines may contribute to the contrasting views. Plant breeders routinely measure levels of genetic advancement each generation and assess the value of novel tools (Atlin et al., 2001). A rigorous re-evaluation process to review research outcomes from the viewpoint of farmers could improve the quality of NRM research.

\section{Pros and cons of market-driven technology development and adoption}

New partnerships across private and public sectors provide innovative examples of R\&E that increase options for farmers to use inputs. In Malawi and Mozambique a number of NGOs are working with researchers, extension and private sector 
groups to develop markets (Bingen et al., 2000). In traditional $\mathrm{R} \& \mathrm{E}$ the focus is on technologies that improve productivity for the current portfolio of crops. This alternative approach involves partnerships to identify market niches and target research to help smallholders meet new opportunities.

Recently liberalized markets in the region have provided an window of opportunity for smallholder involvement in new markets, such as the natural red coloring agent for foods derived from paprika (Snapp, in press). Equal access is not possible for all smallholders, but in the relatively well-endowed environment of Central Malawi $^{3}$ extension staff have worked with NGOs, through secondment arrangements, and private firms, such as Cheetah Paprika, Inc., to review varieties and develop better crop advice. Private-public partnerships allowed extensive training of smallholders in techniques to produce high quality paprika (Toomey et al., 2000). Cross-organizational collaboration reduced risks for smallholders entering new markets, and built the industry.

Revitalizing the pigeon pea industry in Malawi is another example where cooperation is being attempted across diverse organizations, with progress in fits and starts (Jones et al., 2002). The Malawi pigeon pea industry is at a critical stage. Traditional production and dissemination systems are breaking down due to high transaction costs with dispersed traders buying small amounts of low quality products from traditional varieties. There have been sporadic efforts by extension, NGOs and researchers to work with farmers to evaluate pigeon pea varieties in terms of processing traits and on-farm performance (Jones et al., 2002). A key step in this process was a survey of pigeon pea exporters to determine the critical quality traits for the dehulling process. A newly released variety, ICEAP 00040, is a case in point; through collaborative research a high-yield variety has been identified that meets both farmer and industry standards (Snapp and Silim, 2002).

One of the challenges of the market-driven technologies is how to assist limited resource farmers in participating in the production and marketing of cash crops such as paprika for which quality criteria in the markets demand technical skills and inputs. In particular, farmers located far from infrastructure and urban areas face barriers to participation in this type of market-linked research and development (Snapp, in press). Participatory research and extension that involves a range of stakeholders and agents shows promise as a means to address complex training requirements and organizational linkages. This could allow more smallholders to gain access to cash cropping opportunities.

\section{Conclusions}

R\&E services in SSA must: (1) address the need for systematic development of science-based, practical technologies that address real constraints; and (2) improve farmers' capacity to use productivity-enhancing technologies. This will require a

\footnotetext{
${ }^{3}$ Including access to markets and productive soils.
} 
realignment of current $\mathrm{R} \& \mathrm{E}$ activities and processes. Institutional mechanisms and policies must be developed that build in accountability to clients. Soil and crop management advice has become more flexible and cognizant of variable environments and dynamic markets, yet many countrywide blanket recommendations remain in effect. There are cases in SSA where R\&E has even reverted back to highinput approaches. While these types of recommendations might simplify extension, they are also promoting technologies with unacceptably high risks for most small farmers.

Scaling up and facilitating adoption by large numbers of farmers is a major challenge for R\&E. In the short-term, multi-institutional efforts are suggested as a way forward to harness the relative strengths of extension, NGO, universities and the private sector. Research that focuses on impact involves a continued responsibility for developing improved technologies, but must also develop new partnerships with stakeholders and address farmer capacity building, dissemination strategies, market development and the need to increase demand for inputs.

Rigorous screening and systems analysis provides important feedback to keep R\&E focused on priority questions relevant to farmer resources. Participatory research methods can improve technology testing. Teaching participatory methodologies and partnership approaches would be relatively inexpensive investments in improving accountability and client orientation. Our experience suggests, however, that training in participatory methods and innovative approaches is not enough. Organizational reward structures and regular input by farmer-clients need to be in place to support a consistent R\&E focus on smallholder adoption.

\section{Acknowledgements}

The authors are grateful for editor Valerie Kelly and anonymous reviewers who critically read the manuscript and provided valuable input. Sincere thanks are also extended to the dedicated researchers and extension farm advisors we have had the privilege to work with in Africa.

\section{References}

Ahmed, M.M., Rohrbach, D.D., Gono, L.T., Mazhangara, E.P., Mugwira, L., Masendeke, D.D., Alibaba, S., 1997. Soil fertility management in communal areas of Zimbabwe: current practices, constraints and opportunities for change. Results of a diagnostic survey. Southern Eastern Africa Region working paper no. 6, International Crops Research Institute for the Semi-Arid Tropics (ICRISAT), Bulawayo, Zimbabwe.

Atlin, G.N., Cooper, M., Bjørnstad, A., 2001. A comparison of formal and participatory breeding approaches using selection theory. Euphytica 122 (3), 463-475.

Atlin, G.N., Paris, T., Courtois, B., 2002. Sources of variation in participatory variety selection trials with rainfed rice: Implications for the design of mother-baby trial networks. In: Bellon, M.R., Reeves, J. (Eds.), Quantitative Analysis of Data from Participatory Methods in Plant Breeding. CIMMYT, Mexico, DF.

Benson, T.D., 1997. Spatial and temporal variation in fertilizer recommendations for maize grown by smallholders in Malawi. In: Benson, T. (Ed.), Maize Commodity Team Annual Report 1995/1996. 
Department of Agricultural Research, Ministry of Agriculture and Irrigation, Chitedze Research Station, Lilongwe (Malawi), pp. 135-144.

Bingen, J., Howard, J.,Low, J., Massingue, J., 2000. The role of farmer associations in public-private partnerships to accelerate rural development in Zambezia and Nampula Provinces. Trip report. Maputo. MADER/DE/DAP and Michigan State University.

Blackie, M., Gibbon, D., 2003. Enhancing impact: strategies for the promotion of research technologies to smallholders in eastern and southern Africa, a report to the DFID Crop Protection Programme. Natural Resources International Limited, Aylesford.

Braun, A.R., Thiele, G., Fernandez, M., 2000. Farmer field schools and local agricultural research committees: complementary platforms for integrated decision-making in sustainable agriculture. AGREN Network paper no. 105. ODI, UK.

Brown, P., 1962. Provisional Fertilizer Recommendations. Malawi Ministry of Agriculture, Government Printer, Zomba.

Cromwell, Kambema, E.P., Mwanza, R., Chirwa, R., with Kwera Development Center, 2000. Impact of starter pack on sustainable agriculture in Malawi: module 4 of the 1999 starter pack evaluation. Unpublished report, Department for International Development and Ministry of Agriculture and Irrigation, Government of Malawi.

Dimes, Muza, L.J., Malunga, G., Snapp, S.S., 2002. Trade-offs between investments in nitrogen and weeding: on-farm experimentation and simulation analysis in Malawi and Zimbabwe. Paper presented at the 7th Eastern and Southern Africa Regional Maize Conference and Symposium on lowNitrogen and Drought Tolerant Maize, February 11-15, 2002, Nairobi, Kenya.

Donovan, C., Damaseke, M., Govereh, J., Simumba, D., 2002. Framework and Initial Analyses of Fertilizer Profitability in Maize and Cotton in Zambia. Food Security Research Project, Lusaka (Zambia).

Enyong, L.A., Debrah, S.K., Bationo, A., 1999. Farmers' perceptions and attitudes towards introduced soil-fertility enhancing technologies in western Africa. Nutrient Cycling in Agroecosystems 53 (2), $177-187$.

Farrington, J., 1995. The changing public role in agricultural extension. Food Policy 20, 537-544.

Fertilizer Use Recommendation Project (FURP), 1994. Fertilizer Use Recommendations, vol. 1-12. Kenya Agricultural Research Institute, Nairobi.

Franzel, S., Scherr, S.J. (Eds.), 2002. Trees on the Farm: Assessing the Adoption of Agroforestry Practices in Africa. CABI Publishers with ICRAF, New York.

Howard, J., Jeje, J., Kelly, V., Boughton, D., 2000. Comparing yields and profitability in MADER's high- and low- input maize programs: 1997/98 survey results and analysis. Research paper no. 39. Directorate of Economics, Ministry of Agriculture and Rural Development, Maputo, Mozambique.

Johnson, N., Lilja, N., Snapp, S., 2002. Assessing the impacts costs of user participation in research on soil fertility management: The ICRISAT mother-baby trials in Malawi, in: Johnson, N., Lilja, N., Ashby, J., (Eds.) Characterizing and measuring the effects of incorporating stakeholder participation in natural resource management research: analysis of research benefits and costs in three case studies. Working paper no. 17, PRGA, CGIAR. www.prgaprogram.org., 49- 74.

Jones, R., Likoswe, A., Freeman, H.A., 2002. Improving the access of small farmers in Eastern and Southern Africa to global pigeonpea markets. Agricultural Research and Extension Network paper no. 120. Overseas Development Institute, Chatham, U.K.

Kamanga, B., 1999. Soil fertility management and socioeconomic components of farmer participatory research in a southern Malawi watershed. M.Sc. thesis, Department of Crop Science, Bunda College of Agriculture, University of Malawi.

Kamanga, B., 2002. Personal communication from B. Kamanga, University of Malawi graduate student and research affiliate with CIMMYT-Malawi.

Kamanga, B., Kanyama-Phiri, G., Snapp, S.S., 2001. Experiences with farmer participatory motherbaby trials and watershed management improve soil fertility options in Malawi. SoilFertNet Methods working paper no. 5. CIMMYT, Harare, Zimbabwe.

Kanyama-Phiri, G.Y., Snapp, S.S., Kamanga, B., Wellard, K., 2000. Towards integrated soil fertility management in Malawi: incorporating participatory approaches in agricultural research. Managing Africa's Soils no. 11. IIED, UK. www.iied.org/drylands 
Kitch, L.W., Boukar, O., Endondo, C., Murdock, L.L., 1998. Farmer acceptability criteria in breeding cowpea. Experimental Agriculture 34, 475-486.

Levy, S., Barahona, C., 2001. Main report of the monitoring and evaluation programme. Unpublished report, Department for International Development and Ministry of Agriculture and Irrigation, Government of Malawi.

Malawi Ministry of Agriculture and Livestock Development, 1995. Guide to Agriculture Production. Malawi Government Press, Lilongwe Malawi.

Mann, C., 1998. Higher yields for all smallholders through 'best bet' technologies: the surest way to restart economic growth in Malawi. Network working paper no. 3: CIMMYT, Harare, Zimbabwe.

Meertens, H.C.C., 2003. The prospects for integrated nutrient management for sustainable rainfed lowland rice production in Sukumaland, Tanzania. Nutrient Cycling in Agroecosystems 65 (2), $163-171$.

Morrone, V.L., Snapp, S.S., 2001. Uptake of a new on-farm trial design that includes the small-holder farmer. HortScience 36, 477.

Okali, C., Sumberg, J.E., Reddy, K.C., 1994. Unpacking a technical package: flexible messages for dynamic situations. Experimental Agriculture 30, 299-310.

Palm, C.A., Myers, R.J.K., Nandwa, S.M., 1997. Combined use of organic and inorganic nutrient sources for soil fertility maintenance and replenishment. In: Buresh, R.J., Sanchez, P.A., Calhoun, F. (Eds.), Replenishing Soil Fertility in Africa. Special Publication 51. Soil Science Society of America, Madison, WI, pp. 47-61.

Phiri, A.D.K., Kanyama-Phiri, G.Y., Snapp, S.S., 1999a. Maize and Sesbania production in relay cropping at three landscape positions in Malawi. Agroforestry Systems 47, 153-162.

Phiri, R.H., Snapp, S.S., Kanyama-Phiri, G., 1999b. Undersowing maize with Sesbania sesban in Southern Malawi: nitrate dynamics in relation to nitrogen source at three landscape positions. Agroforestry Systems 47, 253-262.

Piha, M., 1993. Optimising fertiliser use and practical rainfall capture in a semi-arid environment with variable rainfall. Experimental Agriculture 29, 405-415.

Place, F., Barrett, C.B., Freeman, H.A., Ramisch, J.J., Vanlauwe, B., this issue. Prospects for integrated soil fertility management using organic and inorganic inputs: evidence from smallholder African agricultural systems. Food policy, doi: 10.1016/j.foodpol.2003.08.009.

Rohrbach, D.D., Okwach, G.E., 1998. Modeling crop performance or cropping decisions. Risk Management for Maize Farmers in Drought-Prone Areas of Southern Africa. ICRISAT and CIMMYT, Mexico, DF, pp. 47-58.

Saka, A.R., 1987. A review of soil fertility and fertilizer recommendations in Malawi, in: Proceedings of East and Southern Africa Fertilizer Management and Evaluation Network Workshop. Lilongwe, Malawi, pp. 93-113.

Snapp, S.S., in press. Innovations in extension from Malawi. HortTechnology.

Snapp, S.S., Heong, K.L., 2003. Scaling up: participatory research and extension to reach more farmers. In: Pound, B., Snapp, S.S., McDougal, C., Braun, A. (Eds.), Uniting Science and Participation for Adaptive Natural Resource Management. Earthscan, UK and IRDC, Canada, pp. 67-87.

Snapp, S.S., Silim, S.N., 2002. Farmer preferences and legume intensification for low nutrient environments. Plant Soil 245, 181-192.

Snapp, S.S., Kanyama-Phiri, G., Kamanga, B., Gilbert, R., Wellard, K., 2002a. Farmer and researcher partnerships in Malawi: developing soil fertility technologies for the near-term and far-term. Experimental Agriculture 38, 411-431.

Snapp, S.S., Rohrbach, D.D., Simtowe, F., Freeman, H.A., 2002b. Sustainable soil management options for Malawi: can smallholder farmers grow more legumes. Agriculture, Ecosystems and Environment 91, 159-174.

Snapp, S.S., Phiri, R.H., Moyo, A., 1998. Soil fertility experimentation by farmers and researchers for drought-prone regions of Zimbabwe and Malawi. Risk Management for Maize Farmers in DroughtProne Areas of Southern Africa. ICRISAT and CIMMYT, Mexico, DF, pp. 13-24.

Sperling, L., Ashby, J.A., Smith, M.E., Weltzien, E., McGuire, S., 2001. A framework for analyzing participatory plant breeding approaches and results. Euphytica 122 (3), 439-450. 
Toomey, D.C., Sterns, P.A., Jumbe, C., 2000. The impact of improved grades and standards on the export potential of targeted commodities in Malawi. Institute for Food and Agricultural Standards. U.S.A.I.D. project report. Blantyre.

Waddington, S.R., Karigwindi, J., 2001. Productivity and Profitability of Maize + Groundnut Rotations Compared with Continuous Maize on Smallholder farms in Zimbabwe. Experimental Agriculture 37, 83-98.

Wendt J.W., 1993. Evaluation of soil fertility and fertilizer recommendations in Malawi, in: Proceedings of Southern Africa Farming Systems-Extension Conference, June 1-3, 1993, Ezulwini, Swaziland. 